\begin{tabular}{|c|l|}
\hline Title & The Current State of High-Tech Pollution \\
\hline Author(s) & YOSHIDA, Fumikazu \\
\hline Citation & ECONOMIC JOURNAL OF HOKKAIDO UNIVERSITY, 26, 21-44 \\
\hline Issue Date & 1997 \\
\hline Doc URL & http://hdl.handle.net/2115/30550 \\
\hline Type & bulletin (article) \\
\hline File Information & 26_P21-44.pdf \\
\hline
\end{tabular}

Instructions for use 


\title{
The Current State of High-Tech Pollution
}

\begin{abstract}
Fumikazu Yoshida
The Water Pollution Control Law, partially revised in May of 1996, greatly helped to rationalize the clean-up system for dealing with " groundwater pollution." This paper aims to investigate the point at issue and the problems of the clean-up system in relation to high-tech pollution throughout Japan. We shall treat the Kimitsu Plant as a clean-up model, and consider what has become of Toshiba Taishi Plant which is the first case of high-tech pollution in Japan. We shall also look at the solution mechanisms for pollution at Kumamoto, which is entirely dependent on groundwater, at the high-tech industrial park pollution of Higashine, at the pollution caused by "high-tech research development plants," at the pollution over the wide area around Yohkaichi, Hadano, which has already enforced the clean-up ordinance, at the pollution caused by high-tech subcontractors, and pollution caused by lens plants. This paper will indicate that, apart from the already-known cases, most cases of pollution have not yet been made public in Japan and that pollution is both widespread and caused by related subcontractors as well as by high-tech plants.

Between districts, the degree of solution and the degree of information differ widely. The reasons depend on the different attitudes of the local government toward the polluter (whether the polluter was invited into the locality or not), the different degrees of dependence on groundwater, and whether any groundwater pollution control guidelines have been drawn up or not. As to the P.P.P., some enterprises refuse to admit formal responsibility of the pollution, but have agreed to pay a part of the clean-up cost as a "contribution." Although few local governments have established a clean-up fund or have prepared a system of renting out clean-up equipment to small-and medium-scale enterprises, it is inevitable that mechanisms to solve pollution must be instituted that correspondent clean-up measures must be undertaken and that the residents must be informed.
\end{abstract}

\section{Introduction}

Japan has waited a long time for a clean-up system to deal with "groundwater pollution". At the end of May, 1996, the Water Pollution Control Law was partially revised. From April, 1997, where there is danger of human health being damaged by hazardous material polluting groundwater, the governor of the prefecture or the ordinance-designated mayor will be empowered to order the 
polluter to take the water quality purification measures, retroactively. Although the revision of the law must lead to progress in water purification, many unsolved problems remain.

The first thing we have to do is to investigate the mechanisms which cause groundwater pollution and then make it clear who is responsible. Human need for groundwater, which is quite different in each prefecture, will determine the progress that has to be achieved and the eagerness with which the pollution mechanism will be controlled.

The second problem is one of solvency. This has to do with whether or not the polluter can pay the clean-up expenses, including the investigation. Does the local government body have to bear the cost in the case of an unspecified source of pollution or when the specified source is an insolvent small enterprise or a plant to which "the designated facility cannot be applied ?" That is why I should like to clarify the current state of high-tech pollution, an example of Japanese geo-pollution, analyzing some characteristic cases.

\section{The Model of "High-Tech Pollution" Clean-up ; Kimitsu City}

The fact of groundwater pollution was made public in September of 1988, a year and a half after the discovery of a polluted spring at Toshiba Component Kimitsu Plant in the Uchi-minowa area of Kimitsu City, Chiba Prefecture. No detailed Japanese investigation of pollution mechanisms had been made before then, but was then carried out by Kimitsu City and Chiba Geo-Environment Research Laboratory.

Based on data produced by the investigation, the clean-up has been dealt with. Toshiba Component Kimitsu Plant employs around 500 workers and produces commutator semiconductor silicon chips, using trichloroethylene in the manufacturing process.

The Kimitsu investigation and clean-up was characteristic of the appropriate measures of selection, development, and enforcement taken by geological specialists in the project team to tackle the pollution mechanism, based on the concept of geo-pollution, which covers such issues as strata, groundwater, and groundair pollution (The Environment Dept. of Kimitsu City, 1993). The pollution source was fixed by the Kimitsu surface layer investigation, which they developed on the spot.

They discovered that there were 7 highly polluted "hot spot" areas. The causal features were revealed by a time series of aerial photographs and the employer's report: 1 , Dumping into an underground waste dumping site near the fifth well ;2, Leakage in refueling of the trichloroethylene tank (The First Production Section) ; 3, Leakage in refueling of the trichloroethylene tank (The Second Production Section); 4, Leakage in refueling of the trichloroethylene tank 
(the Thirty-sixth Building) ; 5, Leakage in replacing waste liquid in front of the cafeteria ; 6, Leakage in carrying waste liquid along the passage from the Second Section of Production to the cafeteria ; 7, Dumping trichloroethylene for cleaning clothes in the passage beside the warehouse.

Upon investigation of 17 borings at 9 spots within the plant site and of 17 borings at 17 spots in the city area, the distribution of aquifer and the actual situation of geo-pollution has been demonstrated, and at the same time a corresponding clean-up technology has been developed.

It has consequently been shown that there was a dual structure of the pollution source in the contaminated building site due to the leakage from the surface facilities and contamination of the underground strata.

Initially, waste substances and contaminated strata were removed, after which heating and air drying treatment was carried out in contaminated strata. To deal with groundwater pollution, pumping and aeration treatments were carried out in each "catchment basin" well, while, for groundair pollution, the sucking method of vaporization and capture of trichloroethylene was adopted.

Secondly, a shield of steel-tubing sheet pile was put in place and the barrier well system was adopted lest contaminated substances from the plant should be diffused within the city area. The contaminated substances and groundwater were effectively discharged from the aquifer.

Thirdly, the clean-up operators were encouraged to pump, aerate, and use the water of public wells in order to remove contaminated substances diffused within the aquifer of the city area. The facilities of Uchi-minowa Sports Park are representative of the utility of public wells. These clean-up measures helped a great deal to reduce the concentration of trichloroethylene in groundwater: to a three-digit number within the plant premises, to a two-digit number near the barrier well, and to approximately ten times the water quality criteria in the city area, when compared with the situation before the clean-up.

The Kimitsu method is extremely important since, for the first time, information about groundwater pollution has been made public, answering to the citizens' uneasiness and their criticism that information had been kept secret for about a year and a half after the incident. Although the total cost of investigation and clean-up has so far amounted to less than $¥ 1.2$ billion, including approximately $¥ 50$ million borne by the city, the P.P.P. has been fundamentally adhered to.

The estimated cost for removing the source of pollution is approximately $¥ 0.2$ billion for installing a steel-tubing sheet pile, digging, transportation, back filling, installation of a catchment basin, triple aerator, and an additional cost of approximately $¥ 60$ million for air drying equipment and so on, all of which were to be paid for by the polluter. As to provision of the barricr well system, the 
polluter bore costs of approximately $¥ 0.1$ billion for installation, and approximately $¥ 3$ million for the annual operating costs. Besides, the cost of the equipment for pumping, discharging, and aeration, approximately $¥ 7.8$ million was to be paid by the polluter, while the annual operating cost, approximately $¥ 8$ million, was to be partially paid by the polluter.

Medical examination of the residents has continued, but so far no abnormal cases caused by groundwater pollution have been reported. Toshiba Component Co., negotiating with the Uchi-minowa Groundwater Pollution Countermeasure Committee representing the residents of approximately 300 households (in other words, approximately 1,000 people) agreed to pay compensation of $¥ 37$ million in April, 1992. It did not, however, include compensation for any future health damage to health.

The Kimitsu groundwater pollution case promoted to amend the Water Pollution Control Law enacted in 1989, and the resultant regulation of groundwater, has had a great effect all over Japan. The discovery of the pollution mechanism and the resultant clean-up technology, which was developed by Kimitsu, have been made public, so that those people who want to learn about the issue may do so.

We shall point out why Kimitsu was able to make such a thorough investigation;

1. Groundwater, including the source of city tap water, was widely polluted.

2. Nippon Steel Kimitsu Plant is located nearby, while the administration had an insight into environmental issues, to say nothing of technical support from the excellent staff of the Geological Environment Research Center of the Prefectural Government.

3. In terms of the relation between the enterprise and the residents, which differs from that obtaining in a company town, the enterprise was able to take a positive attitude toward the investigation and clean-up, using a relatively high standard of technology. The administration, the residents, and the enterprise all cooperated in finding a solution under a joint recognition of the importance of groundwater resources.

\section{What has happened at the Toshiba Taishi Plant since High-Tech Pollution was discovered in Japan for the first time?}

Taishi City, Hyogo Prefecture, is well known as the first known site of groundwater pollution caused by the semiconductor plant in Japan. It is located west of Himeji, is convenient for transport, and has an increasing population. It is also the home of Toshiba's Manufacturing Plant. Groundwater including the tap water supply source was contaminated over the large area by trichloroe- 
thylene. The pollution source was the Toshiba Taishi Plant, formally the Himeji Semiconductor Plant, Ibo district, where trichloroethylene was used for the cleaning of semiconductors and cathode-ray tubes (CRT).

Upon investigation, the soil contamination was found to be caused by problems arising from the "storage and the method of use" of trichloroethylene, stored near the south side of the 407th building of the plant. The digging out of contaminated soil was interrupted by the gushing of groundwater at a depth of 7 meters (Japan Water Pollution Research Association, 1986). The density of trichloroethylene in the plant's shallow well rapidly reduced the standard of the tap water quality, while that of the deep wells retained a high density of about 8,000 ppb. Similarly, in nearby wells, cis-1.2.-dichloroethylene, more poisonous than trichloroethylene, was also detected. Japan Water Pollution Research Association analyzed in 1990 ; Analysis found that a high density of contamination in the deep wells of the plant, caused by the elution of trichloroethylene as a result of boring, had been detained in the soil 35 to 55 meters under the ground, and was eluting further into deeper groundwater. Owing to its low solubility in water, trichloroethylene continued to elute, hardly lowering the density of contamination.

In spite of the disuse of trichloroethylene, trichloroethylene remaining in the soil continued to pollute the shallow well. It was thus necessary to fix exactly the place where the trichloroethylene was detained. In some of the nearby wells, cis-1.2.-trichloroethylene was detected at a higher density than trichloroethylene. This is because cis-1.2.-trichloroethylene originates from the microbial degradation of trichloroethylene. For the thorough solution of "contaminated soil," contaminated soil should in my view be removed during the early stages, and we must recognise the problems caused when trichloroethylene has been stored in the underground for a long time. Inadequate solution merely lengthens the time of pollution. In case of the Fairchild Semiconductor Co., in Silicon Valley in the U. S. A., they dug out soil as far as 40 meters depth at the source of pollution. The first thing necessary to clarify the pollution mechanism is to investigate soil gas in order to trace the pollution source in shallow wells such as those at Kimitsu. Hence we have to return to the basic principles. Cis-1.2.-dichloroethylene is not formated until groundwater is thoroughly polluted, which emphasises the danger of neglecting the first signs of groundwater pollution.

After the discovery of groundwater pollution in the wells of the tap water supply source in Taishi, aeration and activated carbon measures were taken and water supply works were equipped to change from the private well to tap water, but some wells were still used for showers and bath water.

Toshiba Taishi Plant refused to accept official responsibility for pollution, and persisted in not calling the "contributing" conversion costs from the well to 
water supply compensation, only terming it a donation. The Plant substituted 1. 1.1.-trichloroethane for trichloroethylene. Even the response of Toshiba's subsidiary plants is quite different from that of Kimitsu; this is mainly a reflection of whether the local government takes strong action or not. Near Hitachi's Sakura Plant, in Sakura City, Chiba Pref., which produces the same cathode-ray tube as Toshiba Taishi Plant's, trichloroethylene was detected in spring water in the town's outskirts, $170 \mathrm{ppb}$ in the year of 1990, after which pollution of the first aquifer to the third aquifer was discovered by a geo-investigation of the downstream groundwater flow (Sakura City, 1995).

\section{Solution of Groundwater Pollution Mechanism of a City Dependent on Groundwater ; Kumamoto}

Kumamoto City, Kyushu Island, supplies groundwater to all the households of the city. Ten years ago, groundwater was found to be polluted by a chlorinated compound. Although the city water is widely polluted, the pollution mechanism has not yet been fully clarified. In order to analyze the pollution mechanism, both Kumamoto Local Government and Kumamoto City set about a fullscale purification operation, establishing a "pollution clean-up model district" in collaboration with the National Environment Institute of the Environment Agency. Takahiradai district in the north of Kumamoto City has been nominated, and consists of a terrace 80 meters above sea level, with alluvial low land 20 meters above sea level; it is a semi-industrial area, equipped with tap water from a well supply source in the city's outskirts.

In 1987, trichloroethylene was first detected there, exceeding the standard value, but the cause was then unknown. From 1990 to 1991, Kumamoto City Government made an investigation of surface gas and found highly concentrated trichloroethylene soil gas in the building and parking lots of Kyushu Electric Industry, which used to use trichloroethylene, as well as in the neighboring company's parking lot. As the result of executing 14 borings, the investigators found more than $10 \mathrm{mg} / \mathrm{kg}$ of trichloroethylene on the premises, between 20 to 60 meters deep and 30 meters in diameter. Pollution was found to be distributed underground in an "onion shaped" state around the part of highest concentration, and this was regarded as groundwater pollution source (S. Watanabe, G. Higashi, 1994).

As in the case of Kimitsu Toshiba Component, a "double structure of pollution" was discovered here, too. As much as approximately 27 tons of trichloroethylene had been used for cleaning the points of telephone dials by Kyushu Electric Industry for 10 years from 1967 (Kumamoto Nichi-nichi Newspaper dated November 1, 1991). The trichloroethylene was collected by pumping and by the gas absorption clean-up method; since 1994, only the pumping method has 
been used.

Since this was a model case, the total cost of groundwater pollution abatement, approximately $¥ 450$ million, was shared by the Kumamoto local government, Kumamoto City, and the central government. At first, Kumamoto City, considered ordering Kyushu Electric Industry to correct the present conditions, by application of Waste Disposal Act, but found it difficult because in the process of investigation they were not able to confirm the dumping of trichloroethylene (Kumamoto Nichi-nichi Newspaper, December 13, 1991). Later, Kyushu Electric Industry gave Kumamoto City $¥ 30$ million towards the cost of groundwater conservation, but only as a contribution, which means that they do not take formal responsibility for the pollution. In the Water Pollution Law, even in the revised one, one of the points at issue is confirmation that "contaminated waste water has been infiltrating underground."

\section{Groundwater Pollution caused by “High-Tech Industrial Park"; Higashine of the Yamagata Prefecture}

In the Tohoku district as well as in the Kyushu district, many plants related to the semiconductor industry have been built because of abundant manpower and abundant water resources. Near the interchange of an express-highway and airport, "high-tech industrial parks" stand in a row beside the road. The local Government of Yamagata Pref., adjoining Yamagata Airport, developed the Ohmori Industrial Park, so as to invite factories, and since its inception in 1976, 16 companies including high-tech industry have begun operations there. In November, 1991, a local government investigation formally detected trichloroethylene in groundwater of Higashine City for the first time. Yet Yamagata Broadcasting Co., had already reported on the T.V. program "Zoom in the Morning" on April 14, 1989, that 1.1.1.-trichloroethane had been detected in the groundwater on the outskirts of Ohmori Industrial Park by an investigation of its own during March of that year. The Local Government investigation of 1992 reported that trichloroethylene, $2 \mathrm{ppm}$ at a maximum, equivalent to 67 times the standard value, had been detected in groundwater from wells at 35 spots in an area 2.5 kilometers east and west and 1 kilometer north and south of the west side of Ohmori Industrial Park. In periodic monitoring investigations during 1992, "the highest density of trichloroethylene had been detected" (The Yamagata Pref., 1996) and "it was found that a wide area of Higashine was polluted" (The Yamagata Pref., 1995). At Ohmori Industrial Park, the suspected pollution source, five plants had been using such organic solvents of trichloroethylene. The names of the plants are Yamagata Casio, which produces clock, electronic notebooks, metal molds and employs approximately 900 people, Higashine Shin Dengen, which produces semiconductors and employs approximately 320 people, 
Yamagata Sanken, which produces semiconductor chips and employs 550 people, Yamagata Fujitsu, which produces small-sized magnetic disks and employs approximately 1,000 people, Yamagata Kinseki, which produces crystal vibrators and crystal oscillators and employs approximately 500 people (data based on a telephone questionnaire conducted by Yamagata Broadcasting). The local government has already confirmed soil strata contamination at the sites of three business establishments of these companies. One of the enterprises discharged contaminated soil and pumped groundwater from August, 1994, which another enterprise allowed trichloroethylene gas to seep underground from August, 1994, and both these operations have now finished. A further enterprise has also begun to discharge contaminated soil and allow the release of trichloroethylene gas. This area used to be richly abundant in groundwater resources and was so good in quality that its water was very suitable for "fu," a special product of the district. Of the 35 wells whose concentration of trichloroethylene has exceeded the standard value, public tap water has been substituted for well water from 9 of these spots on which the plants depended entirely, at the cost of the City (According to the Living Environment Section of Higashine City). Some neighboring business establishments still utilize contaminated well water, but not for drinking, and Ohmori Industrial Park, in spite of its being the pollution source, continues to utilize as much as 4,500 tons of groundwater a day.

The Environmental Protection Agreement between Higashine City and Ohmori Industrial Park has had little effect on the groundwater pollution problem, and, as a result, the Yamagata Local Government is solely in charge of investigation and guidance. The local government, however, has not yet made public how far the correction of the pollution source and the pollution mechanism has proceeded. As a consequence of the yen's recent appreciation and "Industrial Cavitation," industrial overseas transfer has been promoted, so that some related plants in the Tohoku Electronic zone have been forced to cut down on domestic production, and people in the area can not help getting nervous about the reduction or evacuation of the plants. That is why both the local government and the residents have taken an "indecisive attitude" toward the plants.

\section{Groundwater Pollution caused by Mitsubishi's “High-Tech Research Devel- opment Plant"}

While the semiconductor industry has undergone global development, and recently many Japanese industries have been established in Southeast Asia, domestic semiconductor plants are making desperate efforts to survive as "Research Development Base Plants." For instance, Mitsubishi Electric Kita -itami Plant, located in Izuhara of Itami, Hyogo Prefecture, which employs 3,000 people, is not only the base of research, development and trial production related 
to the semiconductor section of Mitsubishi Electric Company, but also a continuous mass production base of chemical compounds and hybrid semiconductors.

Geo-pollution caused by trichloroethylene has occurred at Kita-itami Plant, too. Groundwater pollution in Itami has been public knowledge ever since Koya, Higashikuwazu, Higashino and Shimogawara in Itami were designated as spots for a groundwater periodical monitoring investigation inquiry by the Hyogo Local Government. In 1989, $360 \mathrm{ppb}$ of trichloroethylene was detected in groundwater at Higashino to the north of Mitsubishi Kita-itami Plant. An outline of the pollution was published but the plant's name was withheld by the person in charge, who worked at the Hyogo Local Government (Toshio Kobayashi, 1993). The report said that upon investigation of well water made by the Public Health Center in 1987, trichloroethylene was detected, after which the Local Government Authority inspected all the plants near the contaminated well to locate the leak from the trichloethylene rinsing tank at the Mitsubishi Kita-itami Plant that had occurred about 1980, and had been already secretly repaired. During a boring inspection within the plant, the investigators decided that the highest density of trichloroethylene in the soil was mainly collected in the first aquifer. At the Kita-itami Plant, so much as 440 tons of trichloroethylene had been used annually. By solidification of the contaminated soil, the density of trichloroethylene in the observed well has decreased, but pollution around the well has not been halted. Nothing has been made public since the discovery of groundwater pollution caused by Mitsubishi Electric Kita-itami Plant. No detailed explanation has been given to us, but it can be said that groundwater around the well continues to be polluted, because $36 \mathrm{ppb}$ of trichloroethylene was detected in groundwater from Higashino, to the north of Mitsubishi Electric Kita-itami Plant, in 1994. (The Hyogo Pref., 1995).

\section{Groundwater Pollution of "A Chrysanthemum and High-Tech Town"; Takefu, Fukui Prefecture}

Takefu, a town of approximately 70,000 people in Fukui Prefecture on the JR Hokuriku Line, a famous city for "Chrysanthemums and High-Tech," is proud of its record as the prime shipper of manufactured products in Fukui Prefecture. About $40 \%$ of both the products shipped and the employees of the town are related to electric machine appliances. Upon investigation by the Local Government in 1989, groundwater pollution was discovered in Takefu, too. $85 \mathrm{ppb}$ of trichloroethylene, exceeding the standard value, was detected at Honbo, within the town's boundary.

At first, this was regarded as pollution by an unknown cause as no plants in Honbo used trichloroethylene. Prof. Isamu Tsugo of Fukui Industrial Vocational High School, now Professor Emeritus, was asked to investigate the groundwater 
by the town Mayor, and he commenced a fundamental investigation in January, 1990. Upon investigation of at least 200 wells, Prof. Tsugo suspected that the pollution source was the Fukui Murata Plant, upstream of the groundwater, located at Okamoto of Takefu, producing ceramic condensers, and employing 2,600 people. Pollution had spread along the old-river line of the Yoshinose River, about 1 kilometer at most and about 100 meter at least in width, and extended for about 6 kilometers in length. The pollution had extended nearly as far as the tap water resources of the neighboring city, Sabae, and the highest detected density of trichloroethylene was $200 \mathrm{ppb}$ (C. Okumura, I. Tsugo, 1992).

When under the guidance of Fukui Prefecture, the Fukui Murata Plant made boring investigation at 25 plots within its site, trichloroethylene was detected in all of them, especially in 3 plots near the semiconductor plant site, in the strata 2-4 meters underground ; the density of trichloroethylene ranged from $1,000 \mathrm{ppb}$ to $2,400 \mathrm{ppb}$. Contaminated soil spread over about 2,000 square meters. The Local Government said that the semiconductor plant had stopped using trichloroethylene in 1986 and had remodeled the building as an office in 1988. The Local Government said that "so as not to diffuse pollution by digging soil," (The Fukui Newspaper dated July 7, 1993) they took clean-up measures of vacuum and pumping. Professor Tsugo's investigation revealed that the Plant had been very careless about the way it had stored trichloroethylene, that it had scattered trichloroethylene as herbicide, and that it had not paid the cost of changing from polluted groundwater to tap water. The 1993 groundwater periodical monitoring carried out by Fukui Prefecture said that although pollution as high as $81 \mathrm{ppb}$ of trichloroethylene had continued to spread, for lack of fundamental prevention measures, owing to its sensitive economical dependence on Fukui Murata Plant, the Fukui Prefecture and Takefu City had taken an indecisive attitude toward groundwater pollution. The Murata Plant was singled out as a similar groundwater pollution source to other ceramic condenser factories, such as the Yohkaichi Factory, of Yohkaichi, Shiga Prefecture. Two more cases of large-scale groundwater pollution have been confirmed in Takefu. One is trichloroethylene groundwater pollution caused by Takefu Matsushita Electric Co., near Oushio Station of the Hokuriku Line (located in Imajuku of Takefu, which produces power generators and electric motors and employs approximately 1,000 people). It is said that Takefu Matsushita Electric Co., concerned about the possible effects on the neighboring Hokuriku Coca-Cola Bottling Co., has already taken pumping measures to clean-up the groundwater. Another case of tetrachloroethylene groundwater pollution is one caused by the Takefu Plant of the Shin-etsu Chemical Industry, near JR Takefu Station (located in Kitafu of Takefu, which produces silicon, rare earth and employs 500 people), and the Takefu Plant of Shin-etsu Semiconductor Industry. 
Thus Takefu, famous for "Chrysanthemums and High-Tech," is urged to take a fundamental measures against pollution unless it is to become known as " the city of High-tech pollution."

\section{The Most Serious Case of Japanese High-Tech Wide Area Groundwater Pollution; the Outskirts of Yohkaichi, Shiga Prefecture}

The outskirts of Yohkaichi of the Shiga Prefecture are the most widely polluted parts of Japan. According to the tap water source quality survey for all Japan, three times the standard of trichloroethylene has been detected in the public water supply from southern sources at Azuchi, Shiga Prefecture. On further investigation of groundwater in private wells in Azuchi and the outskirts of Yohkaichi and Ohmi-hachiman, a volume of trichloroethylene over the standard amount was detected in 27 wells over a wide area of 40 square kilometers, more than 10 kilometers in length from the outskirts of Yohkaichi Interchange of the Meishin Express Way to the City Area of Azuchi and the northwest parts of Ohmi-hachiman. The highest density was $1,770 \mathrm{ppb}$ within the city area of Yohkaichi, specifically Seiwa, and the most heavily polluted area was near Meishin Yohkaichi (Japan Water Pollution Research Association, 1986). 9 plants within the pollution area, located in the central industrial park, used trichloroethylene and 379 tons of the total amount of trichloroethylene was consumed by 7 plants. 3 of these 7 electric machine appliances plants were Yohkaichi Business Establishment of Murata Factory, located in Higashi-okino of Yohkaichi, producing ceramic condensers, resistors, circuit products and employing 1,300 people, Yohkaichi Factory of Kansai NEC Electric, located in Myohoji of Yohkaichi, producing diorde and employing 260 people, Toppan Printing Electronics Plant Myohoji of Yohkaichi, producing parts for electric appliances and communication machines, such as color filters, and employing more than 500 people. Of the remaining 4, one is the Yohkaichi Factory of the Daishowa Paper Industry, producing pulp, paper, and paper processed goods, located in Myohoji of Yohkaichi, and employing more than 500 people. Another is the Toyo Radiator Yohkaichi Plant, located in Gochi of Yohkaichi, producing transfer mechanical appliances, car coolers, and heat exchangers, and employing 500 people. Another is the Toppan Printing Shiga Plant, located in Myohoji Town of Yohkaichi, printing, publishing, and producing building printing. The fourth is Takiron Yohkaichi Plant, located in Higashi-okino of Yohkaichi, producing agricultural civil engineering material products, such as hard PVC (polyvinyl chloride), coating iron wire and so on, and employing 160 people (Japan Water Quality Pollution Research Association, presumed from Table 4.2.3. of 1986). Two of the abovementioned companies, Daishowa Paper Industry and Toyo Radiator, discharged water contaminated over the effluent standard. While two electric machine appli- 
ance companies, Daishowa Paper Industry, Toppan Printing Co., and Takiron Co., used a huge amount of groundwater exceeding the standard (from February to July of 1984, presumed from Table 4.3.2. of Japan Water Quality Pollution Research Association, 1986). Finding it difficult to specify the cause of pollution, the Siga Prefecture gave guidance on how to reduce organic solvent's seeping underground. They advised that water wells should be provided for 2 business establishments, that aerators should be newly equipped to 4 plants, that absorption of activated carbon should be installed to 1 plant, and that 3 plants should be changed in depth of their water wells. By July, 1985, no business whose trichloroethylene was seeping underground, exceeded the controlled target value, although even at this time, we may notice that one business establishment still allowed organic solvent to seep underground. Subsequent investigation of groundwater pollution revealed;

1. trichloroethylene was detected at much higher density than tetrachloroethylene and 1.1.1.-trichloroethane and was distributed around the heavily polluted zone in a belt. Groundwater was polluted, without any diffusion, in the direction of the upper to the lower reaches of the old river basin.

2. There was little change in the distribution of contamination by trichloroethylene. These findings may be because in the aquifer of the soil near pollution sources, the indissoluble trichloroethylene which remained began to dissolve gradually owing to fluctuations of the water table and was carried by the stream of groundwater.

Although it is said that pollution source, as mentioned above, must be the group of plants near the interchange of the Meishin Express Way, Dr. Kunihiro Yamada is suspicious of the Yohkaichi Business Establishment of the Murata Factory, from the point of view of the scale of the plant and estimated quantity of organic solvents that it uses (Kunihiro Yamada, 1985). Even today, there has been no reduction in the scope of pollution (Yohkaichi, 1993). In the Shiga Prefecture investigation of 1994, trichloroethylene was detected in 15 of 20 spots, and, to our surprise, exceeded the standard, especially in 6 of the 15 spots (Shiga Pref., 1995). Even in the most seriously polluted area, the pollution mechanism has not been corrected and, therefore, fundamental clarification of the problem has been left untouched.

\section{Hadano Groundwater Pollution under the Pollution Control and the Clean up Ordinance.}

Hadano, with a population of 160 thousand, a city famous for " the beautiful spring of Kobo" and "a group of springs of the Hadano Basin," is located at the foot of Tanzawa in the mountainous district of Kanagawa. In January, 1989, a 
weekly photography magazine made public that Hadano, spring was polluted by tetrachloroethylene $(34 \mathrm{ppb})$. Yet the 1983 Japan tap water source quality survey had already confirmed that Hadano was polluted by organochlorine chemical substance, although the level was below the prescribed standard.

Since Hadano had set up a water supply business in 1890,65\% of its tap water source has been supplied by groundwater from the "natural water jar." The city is equipped with 56 fountain head wells, 29 water distribution systems, and many private wells. Since groundwater pollution was confirmed in 1989, Hadano has installed aerators to 4 of its water distribution systems and transferred private wells to the water supply system. The industrial park, where many business establishments have continued to use chlorinated chemical substances, is located in a groundwater recharge area just at the center of the basin, and the polluted area consists of approximately 12 square kilometers within the city along both sides of Mizunashi River running through the city center. Hadano, which is taking the situation very seriously, immediately investigated the matter in order to combat groundwater pollution mechanism. Since 1990, they have continued to analyze the area, by boring and installing observation wells (Hadano, 1993).

An investigation of the groundwater along the left bank of Mizunashi River running through Soyahara Industrial Park reported:

1. In spite of the very narrow pathway of the second gravel layer, pollution infiltrated the third gravel layer vertically in times of drought, every six months.

2. In the third gravel layer, the river flows slowly through, where groundwater pollution has spread.

3. The third gravel layer was polluted by the upstream waters of the Mizunashi River along the fourteenth municipal road, and the scope for pollution of the third gravel layer has spread rather widely along the left bank.

The right bank of Mizunashi River, where Hadano Technical Park and Hirasawa Industrial Park are located, was found to be polluted:

1. The pollution pathway and scope for pollution were very narrow in both the second and third gravel layers.

2. The areas of Hirasawa and Imaizumi spring water were assumed to be contaminated by pollution of the right bank and pollution of the fourth gravel layer of the left bank.

The Japan Academic Water Environment Association confirmed in 1992 that 60 meters deep wells in the left bank of Mizunashi River were polluted by 95 to $866 \mathrm{ppb}$ of trichloroethylene and 129 to $143 \mathrm{ppb}$ of tetrachloroethylene. This report established the depth and the area of pollution. 
Hadano inspected those business establishments which were using chlorinated compounds, and consequently by 1992, 58 business establishments was forced to stop using chlorinated compounds, 27 substituted another substance, 31 improved their methods of use, and 27 improved their methods of storage (Hadano City, 1993). At the same time, Hadano confirmed that 63 business establishments had carried out simple surface soil investigations with a boring bar detection tube as against 131 business establishments in total which were still using or had used chlorinated compounds, in order to make " a general investigation" of groundwater pollution, the work being covered by the municipal budget. In addition, they inspected storage of new and waste liquid which was then in use and out of use. Types of business and business establishments were classified with some exceptions into main three kinds: metal product manufacturing, electric mechanical appliance manufacturing, and transport mechanical appliance manufacturing (According to Environmental Conservation Section of Environment Dept. of Hadano). Hadano made "the fundamental investigation" of 63 companies (the cost was covered by the City), and included boring, from 1991 to 1994. 44 of the 63 companies made a "detailed investigation" by themselves, at their own cost, and consequently started a clean-up business of their own (The remaining company was cleaned up by the Fund).

The methods used by the 44 companies who by 1995 had enforced clean-up business, are low heat processing, adopted by 3 companies, industrial waste treatment, 5 companies, soil containment gas absorption processing, 2 companies, original location gas absorption processing, 33 companies, pumping aeration processing, 1 company (Hadano City, 1996). After 22 companies, including two laundries, had completed clarification, approximately 9 tons of organic solvent was collected.

In Hadano Industrial Park, regarded as the groundwater pollution source, many major manufacturers involving high-technology and its related companies have been built. On the left bank of Mizunashi River, we can find, among others, Topra (manufacturing small screws and bolts and employing 230 people), Shinko Air Conditioning Industry(manufacturing air conditioning appliances), Stanley Electric (manufacturing car electric products and semiconductors and employing 1,700 people), Nikko Electric Industry (manufacturing internal combustion engine electric products and employing approximately 200 people), Yokokawa Electric Appliance (manufacturing defense appliances and employing approximately 30 people), Nittan Valve (manufacturing valves), Toshiba Ceramic (manufacturing quartz glass and employing 140 people), Toyo Radiator (manufacturing radiators and oil coolers and employing 500 people), Nippon Inter (manufacturing semiconductor commutators and employing 640 people). Still in Hadano Techno Park, on the right bank of Mizunashi River, we find 
Shimazu Plant (manufacturing electro magnetic analysis equipment and semiconductor manufacture equipment, employing 200 people), Nissan Car Body (manufacturing car parts and employing 80 people), Tokyo Electric (manufacturing cleaners and small motors and employing 600 people), Hitachi Plant (an electronic computer system manufacturer). In Hirasawa Industrial Park, Kobe Steel has built a plant for steel pipes for air conditioning and employs 430 people. The names of the business establishments which have dealt with the clean-up of groundwater pollution have not been made public, but no doubt some of the above-mentioned enterprises will be among them.

Hadano, which has already established a Groundwater Usage Cooperation Fund System for groundwater preservation, and has taken the opportunity to check groundwater pollution, has led the country in enforcing the Groundwater Contamination Control Clean-up Ordinance, “Japanese Super Fund." (Fumikazu Yoshida, 1995). From 1989 to 1995, Hadano spent approximately $¥ 360$ million in total for groundwater pollution investigation, and has saved approximately $¥ 50$ million of the fund. The Hadano Groundwater Pollution Clean-up Business has been run on one tenth of the expenditure estimated in 1991. This is partly because a very efficient clean-up system has been developed by the enterprises, and operated at a unexpectedly low cost. Nevertheless, problems regarding the solution of the pollution mechanism, the clean-up measures, and public information remain. Taking no account of its city's large dependence on groundwater, the Hadano Local Government developed a high-tech Industrial Park just within the groundwater recharge area, which must be the principle cause of complicated pollution. When we consider the current general use of organochlorine chemical compounds, it can be said that if the same investigation as that made by Hadano is carried out in other areas, geo-pollution is sure to be found out everywhere.

\section{Groundwater Pollution by High-Tech Subcontractors}

Some, at present, high-tech products are made up of many individual parts, many subcontractors have built factories all over Japan and throughout Asia. This means that groundwater pollution is likely to be caused by high-tech subcontractors not only in big cities but throughout Japan. For instance, in Fukushima Prefecture, the Fukushima Local Government required enterprises to pay the cost of clean-up business of the strata and groundwater polluted by organochlorine chemical compounds. The enterprises affected by the enforcement of the clean-up extended to 36 districts (Kahoku Shimpo Newspaper dated August 13, 1993). Three of the cases related to the makers of electronic parts. One of the manufacturing plants, in Itozawa, Tajima, South Aizu County, deals in communication appliances and electronic appliances. After the discovery of pollution in 1989, the plant cleaned-up the polluted strata. Another of the plants, at Kinosa- 
ki, Naganuma, Iwase County, manufactures computer terminal units. When groundwater was found to be polluted by trichloroethylene, they pumped out the polluted groundwater (The Fukushima Prefecture, 1992). The Bullet Train Motor Manufacturing Plant of Hattanda, Kawamata, Date County, with approximately 200 employees, has an association with Toshiba. In 1989, the plant was found to be polluted by tetrachloroethylene. In addition, in Fukushima Prefecture, much groundwater pollution has been caused by subcontractors of precision machinery related to the making lenses.

In Machida, Tokyo, groundwater pollution has spread around the areas of Tsuruma and Kanamori (Living Environment Section of Environment Department of Machida City, 1990). The pollution mechanism was investigated by the Environmental Science Institute of Tokyo, which plans to solve the groundwater pollution mechanism relating to trichloroethylene, first detected at the site of the electronic part plant 10 years ago. The Institute has reported that in Machida City, the combined effect of the amount of precipitation, the groundwater level, and the concentration of pollutants, following the rise of the groundwater table, reacted on the stagnant silty part of water permeability, which resulted in an increase in the concentration of pollutant in the groundwater. In Mobara City, Chiba Prefecture, upon investigation of the pollution mechanism and upon investigation of the distribution of ground pollution in the strata pollution plume and surface soil pollution, named the Electronic Appliance Parts Manufacturing Plant, which uses trichloroethylene (Toshiba Component Cooperative Plant, employing 40 people), as the pollution source (Asahi Newspaper dated December 8 of 1989).

Similarly, in Awa-chikura, Chiba Prefecture, the groundwater pollution mechanism caused by trichloroethylene was corrected, and the Condenser Plant (An Affiliated Company of Hitachi AIC, employing 60 people) carried out the clean-up by digging and removing contaminated strata, by ground-air absorption, and by suction well for drawing off contaminated groundwater.

As to the groundwater of Tochigi City and Tsuga Town, Tochigi Prefecture, both partially contaminated by trichloroethylene, much trichloroethylene was detected at as high a density as $4,400 \mathrm{ppb}$ in a drain from a side ditch at the Electrolysis Condenser Co., Nishikata, Kamitsuga County, after which a large amount of trichloroethylene was also detected in the soil strata. The plant granted the residents an on-the-spot inspection at the request of the Tomihari neighborhood self-governing body of Tsuga Town and presented an improvement plan to the Tochigi Prefecture. The improvement plan says that in order to prevent underground leaking, the company installed a stainless steel saucer under the trichloroethylene rinsing tank, a tied storage tank with a pipe, lest groundwater should be polluted by leaking trichloroethylene. The drain, which carried 
highly condensed trichloroethylene, and contaminated the soil strata, was pumped dry and aerated (Shimotsuke Newspaper dated July 5 of 1992).

In March of 1992, in Fukushima, Yatsuo Town, Toyama Prefecture, groundwater of an Electron Parts Plant was found to be contaminated by $43 \mathrm{ppb}$ of trichloroethylene. Trichloroethylene was detected in samples of 12 soil strata in 19 spots within the factory site, while the concentration was highest on the outskirts of the trichloroethylene depository (Gas concentration was $300 \mathrm{ppm}$ ). 40 tons of contaminated soil strata were removed and a follow-up survey of contaminated well was maintained ; from $35 \mathrm{ppb}$ to $92 \mathrm{ppb}$ of trichloroethylene were detected in 1993 (Toyama Prefecture, 1992, 1993).

\section{Groundwater Pollution by Lens Plants}

It was in July of 1990 that tetrachloroethylene was detected in groundwater at Shirakuwata, and the Sendo district of Kanuma, Tochigi Prefecture, whose special product, Kanuma Soil, is well known. After the Housing Reclamation Trader (Toda Construction) asked the Public Health Center for a groundwater quality test, the groundwater turned out to be polluted $(7,850 \mathrm{ppb}$ at highest). Pollution had spread from the area of the intersection of the Tohoku Driveway and the JR Nikko Line to low land of the Takeshi River Valley, about 2 kilometers long and 300 meters wide. Since well water was used by 56 of 186 households in this district, the residents panicked as soon as they knew of the groundwater pollution (Shimotsuke Newspapers dated both August 8 and August 19, 1990). Although tetrachloroethylene is generally known as a contaminant of the cleaning industry, in the case of Kanuma, the investigation of the Tochigi Prefecture assumed that the Cannon Kanuma Plant, at that time employing 220 people, upstream of the groundwater was the pollution source. Upon detailed investigation, the groundwater of 21 wells supplying 369 households in the area was found to exceed the standard value. The plant annually consumed 240 tons of tetrachloroethylene in an undiluted solution for cleansing the grinding process of copy machines and camera lenses. They absorbed the tetrachloroethylene by activated carbon and then poured the treated waste water into a side ditch. The factory has already been accused by the residents of its impermeable waste water. Tetrachloroethylene was detected in the waste water, exceeding the standard value. The undiluted solution, which was used for cleansing, was accumulated in six underground waste liquid tanks, which were collected by an industrial wastes disposal business. There was, however, a leak from both the cleaner waste liquid tank and the distillation reprocessing apparatus, which were then under repair. Under the improvement order passed by Tochigi Prefecture, the plant presented an improvement plan to set up a new aerator at the final discharge outlet, to exchange activated carbon for fresh carbon, and to set up an aerator in 
the coagulating sedimentation disposal process (Shimotsuke Newspaper dated August 19, 1990). Although the plant was closed the following year, pumping aeration disposal was begun from January, 1991 by digging 3 barrier wells within the plant site as a means of groundwater pollution abatement. At the same time, pumping aeration disposal was carried out to set up a new barrier well outside the plant. The residents established the Tsuda-Sendo District Pollution Countermeasures Committee and negotiated with Cannon through Kanuma City Hall. As a result of the negotiation, Cannon prepared a memorandum in September of 1990 , to the effect that Cannon would pay $¥ 600,000$ per household, $¥ 28$ million in total in compensation for pollution damage. As to health clamage, 70 people in the polluted area underwent medical examinations at the end of 1990, and no abnormal symptom were said to be found (Shimotsuke Newspaper dated January $25,1991)$.

The pollution mechanism solution has still not been made public, however, and therefore the extent of groundwater pollution is not clear ; as a result, Tochigi Prefecture has not been able to designate Cannon as the pollution source. Now that damage compensation has been paid, the clean-up has been deferred. The cost of a long-term groundwater aeration pumping is likely to be covered by public expenditure. The case of Cannon Kanuma Plant is characteristic of leaks from underground tanks storing tetrachloroethylene used for lens cleaning.

A similar case of groundwater pollution occurred at the Cannon Fukushima Plant, with approximately 1,500 employees. The plant used to produce a singlelens reflex camera and an $8 \mathrm{~mm}$ video, but has now turned to the exclusive production of $8 \mathrm{~mm}$ video. The investigation of Professor N. Chuman, the Administration and Sociology Department of Fukushima Univ., found groundwater pollution of trichloroethylene and 1.1.1.-trichloroethane in the plant location at Sakurashita, Fukushima City to Kato, approximately 1.3 kilometers long, approximately 100 to 400 meters wide, and approximately 35 hectares in area (N. Chuman, 1992).

Although the Cannon Fukushima Plant did not formally admit pollution, they have covered the cost of converting the water supply in the polluted land.

In Fukushima Prefecture, much groundwater pollution has been caused by small- and medium-scale lens makers as well as above-mentioned case ( $N$. Chuman, 1996). The case of the Fukushima Prefecture is not exceptional from a nationwide point of view, and it is thought that extensive groundwater pollution has been caused by small- and medium-subcontractors related to precision machine production has spread throughout Japan.

\section{Conclusion}

As we can see from the above account, pollution caused by high-tech plants 
and related subcontracting plants has spread throughout Japan and other than the cases mentioned here most instances of pollution have not yet been made public. As I argued in my previous paper (Fumikazu Yoshida, 1995), we need to combat and correct the pollution mechanisms in terms of the importance of geo-pollution and the significance of clean-up, we must put the corresponding clean-up countermeasures into effect, and must establish a responsible guidance and regulatory organization system which can convince the residents of the effectiveness of the treatment. Among the prefectures, there are differences in the degree of the solutions devised and the publication of pollution mechanisms. This is due to the different attitudes of authorities towards the polluter, the various degrees of public dependence on groundwater, and the legal provisions, made by such edicts as the Groundwater Pollution Control Ordinance and so on.

It would be a large future assignment to proceed with the "groundwater clean-up " according to the partially amended Water Pollution Control Law. As for the P.P.P., some enterprises refuse to admit their responsibility for pollution officially, and instead pay some of the clean-up expenses as " a contribution." It would be much more important for the administration to make clear the relation between pollution and its past causal beginnings. In the case of a small- and medium-scale enterprises, unable to clean up, the responsibility of the related parent company or the financing company should be the subject of investigation, as it is in the United States of America.

Although some local government bodies have raised a fund and established a system of renting the clean-up facilities, the fund and the system are based on public funds, and it is indispensable to make clear the responsibility of the enterprise as polluter and not to hide the information from the public of pollution mechanisms and purification measures.

Professor of Economics, Hokkaido University

\section{References (in Japanese)}

1. Asahi Newspaper. (1989), "Trichloroethylene has been detected at Mobara, Pollution Source is Mobara Giken" (dated 8th December), Chiba Edition.

2. N. Chuman. (1992), "Groundwater contamination with Chlorinated Solvents in the Southern Fukushima Basin, Northern Japan" in The Annual Report of Synthetic Study at Fukushima University, Nature and its Humanization, No. 3, 1992. pp. 19-29.

3. N. Chuman. (1996), "Outline of the Groundwater Contamination by Chlorinated Solvents in Fukushima Prefecture, Japan" in The Annual Report of Synthetic Study at Fukushima University, Nature and Its Humanization, No. 4, 1996.

4. Fukui Newspaper. (1993), "Chlorinated solvents is detected at factory sites" (dated 7th of July).

5. Fukushima Prefecture. (1992), The Annual Report of Environment Center at Kohriyama, Fukushima Prefecture, p. 59.

6. Hadano City. (1993), General View of Environment Counter Measures, p. 78.

7. Hadano City. (1996), Clean-up of Geo-Pollution by Simple Clean-up System, p. 87. 
8. Hyogo Prefecture. (1995), White Paper of Environment, p. 53.

9. Kahoku Newspaper. (1993), "Rethinking of Water, Fukushima City(3)" (dated 13th of August).

10. Department of Environment, Kimitsu City. (1993), The First Report of Clean-up Measures of Geo-Pollution.

11. T. Kobayashi. (1993), "Restoration of Groundwater Contamination by trichloroethylene" Situation and Clean-up Measures of Groundwater and Soil Contamination, Kogyo Gijutsukai, pp. 402-405.

12. Kumamoto Nichi-nichi Newspaper. (1991), "Clean-up Experiment will start later this month" (dated 1st of November).

13. Kumamoto Nichi-nichi Newspaper. (1991), "How about companies responsibility?" (dated 13th of December).

14. Department of Environment, Machida City. (1990), Survey of Groundwater Contamination by Chlorinated Solvents.

15. Japan Water Pollution Research Association. (1986), Groundwater Conservation Measures Research, Case Study, pp. 116-142, 149-183.

16. Japan Water Pollution Research Association. (1990), Groundwater Safety Research, Case Study, pp. 67-107.

17. Japan Academic Association of Water Emvironment. (1992), Fundamental Study of Soil and Groundwater Contamination by Toxic Substances, Case Study, p. 29.

18. M. Okumura and I. Tsugo. "Survey for Groundwater Pollution by Trichloroethylene in Tan-nan Area" The Annual Study Report of Fukui Industrial Vocational High School, No. 26, pp. 199-206.

19. Sakura City. (1995), White Paper of Environment, No.17.

20. Shiga Prefecture. (1995), White Paper of Environment, p. 112.

21. Shimotsuke Newspaper. (1990), "Groundwater Contamination, Fears spread" (dated 8th of August).

22. Shimotsuke Newspaper. (1990), "Cannon is trying to improve facilities" (dated 25th of August).

23. Shimotsuke Newspaper. (1991), "Health Effect is not confirmed" (dated 25th of January).

24. Shomotsuke Newspaper. (1992), "Groundwater Contamination at Tsuga, Tochigi" (dated 5 th of July).

25. Toyama Prefecture. (1992) (1993),. The Annual Report of Toyama Environment Center, No. 20, pp. 36-37, No.21, p. 35.

26. K. Yamada. (1985), "Warning from Groundwater(2)" Gijutsu to Ningen (Technology and Man), April 1985, p. 23.

27. Yamagata Prefecture. (1996), Survey of Groundwater Quality.

28. Yamagata Prefecture. (1996), White Paper of Environment, pp. 33-34.

29. Yohkaichi City. (1993), Environment of Yohkaichi, p. 18.

30. F. Yoshida. (1996), "Geo-Pollution and a Clean-up System" Economic Journal of Hok kaido University, Vol. 25 (in English).

31. M. Watanabe et al. (1992), "Studies on Pollution Mechanism of Undergroundwater(2)" The Annual Report of Tokyo Metropolitan Institute of Environment, pp. 179-185.

32. S. Watanabe et al. (1994), "Clean-up of Geo-Pollution by Chlorinated SolventsKumamoto" Kikan Kankyo Kenkyu (Quarterly Environment Study), No. 95, pp. 53-69. 


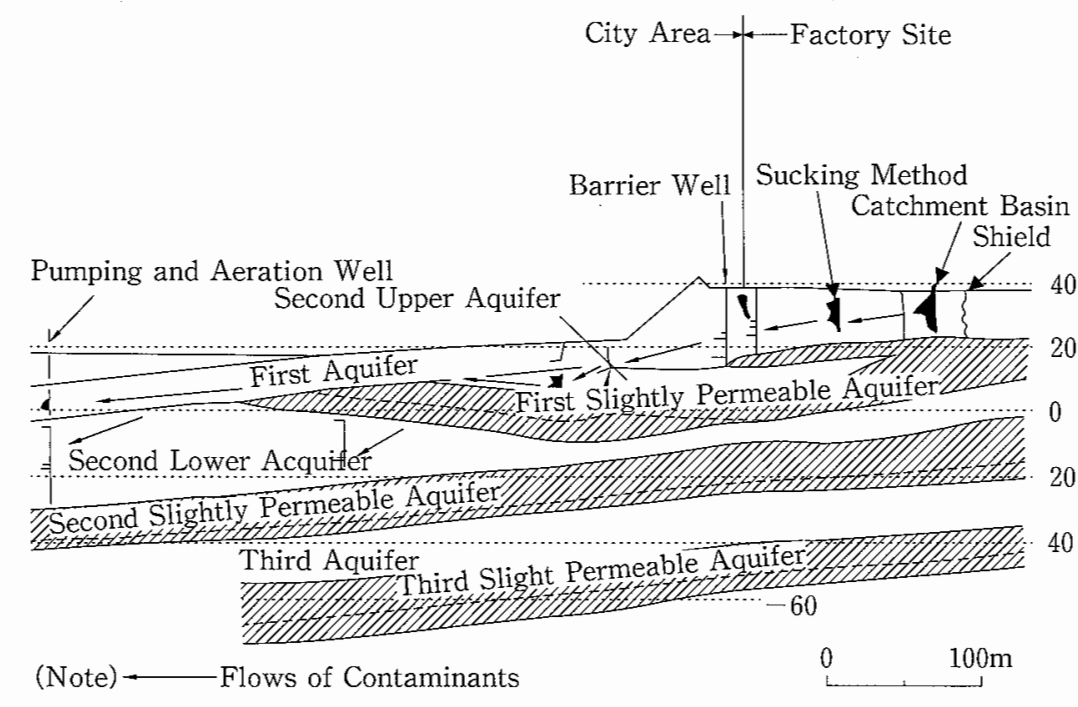

Map. 1. The Geo-Pollution and Clean-up Technology at Kimitsu (Dep. of Environment, Kimitsu City, 1993)

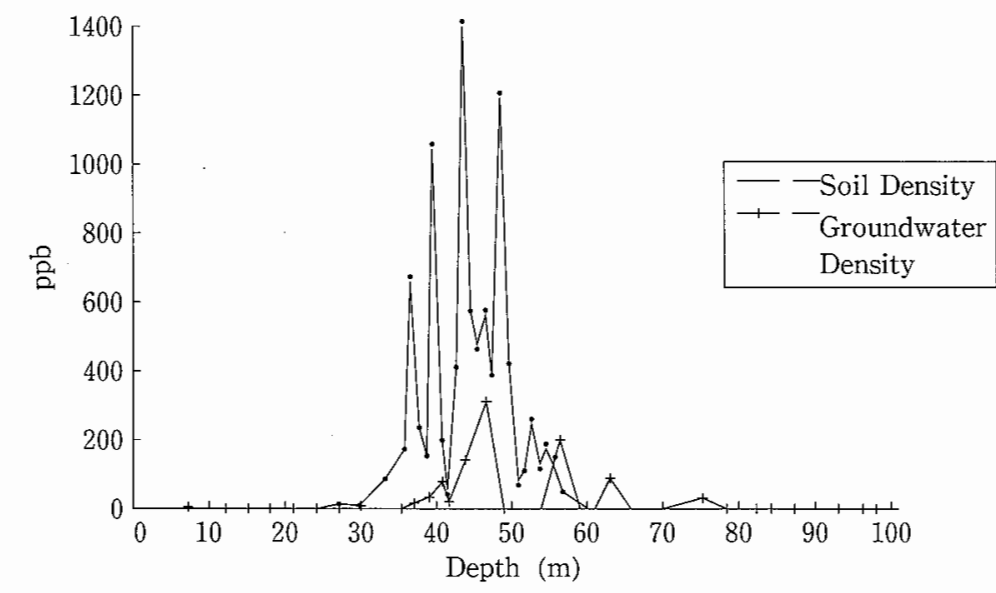

Map. 2. The Density of Trichloroethylene at Toshiba Taishi Plant (Japan Water Pollution Research Association, 1990, p.102) 


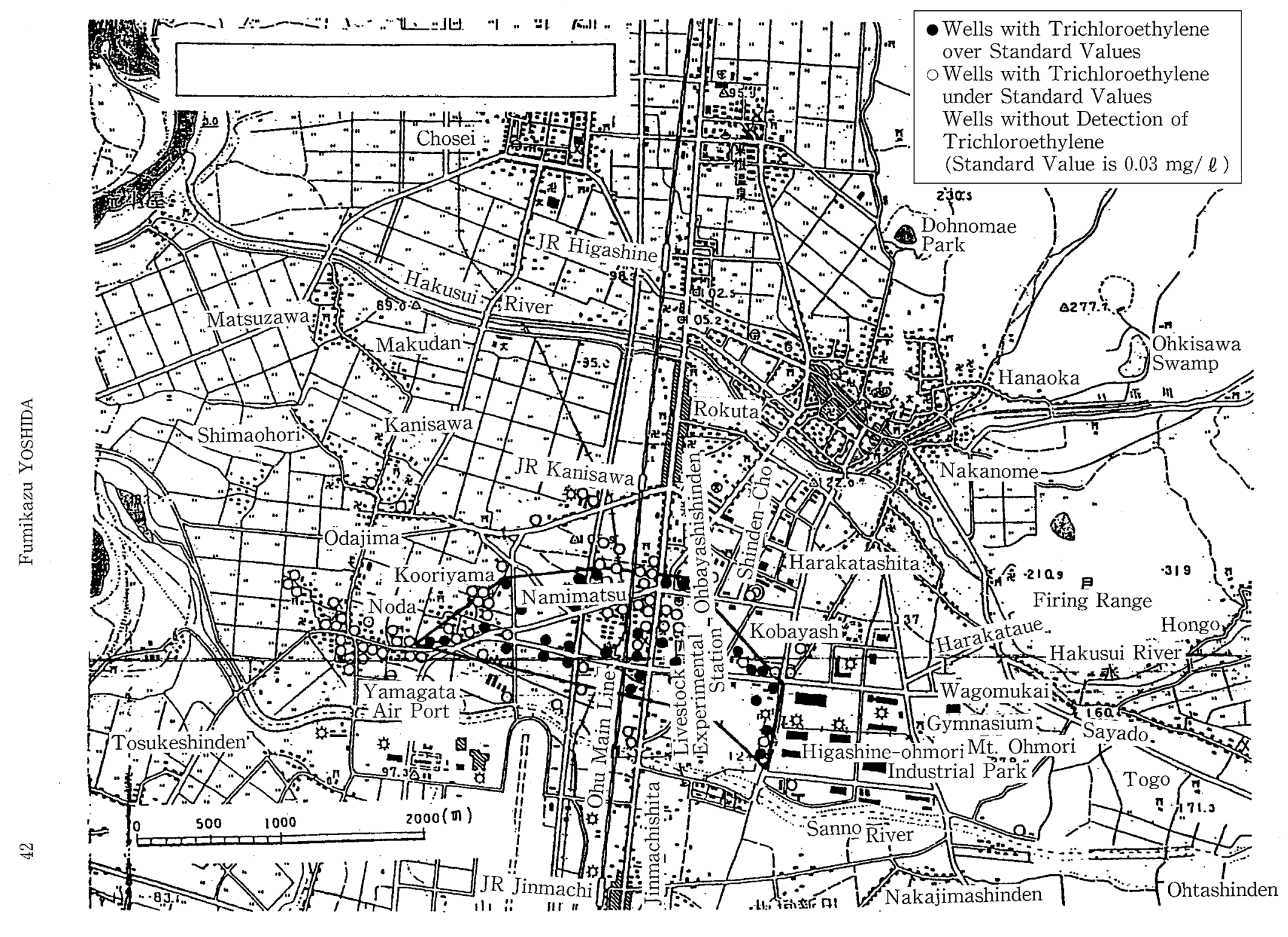

Map. 3. The Groundwater Pollution at Higashine

(Yamagata Prefecture, 1993) 


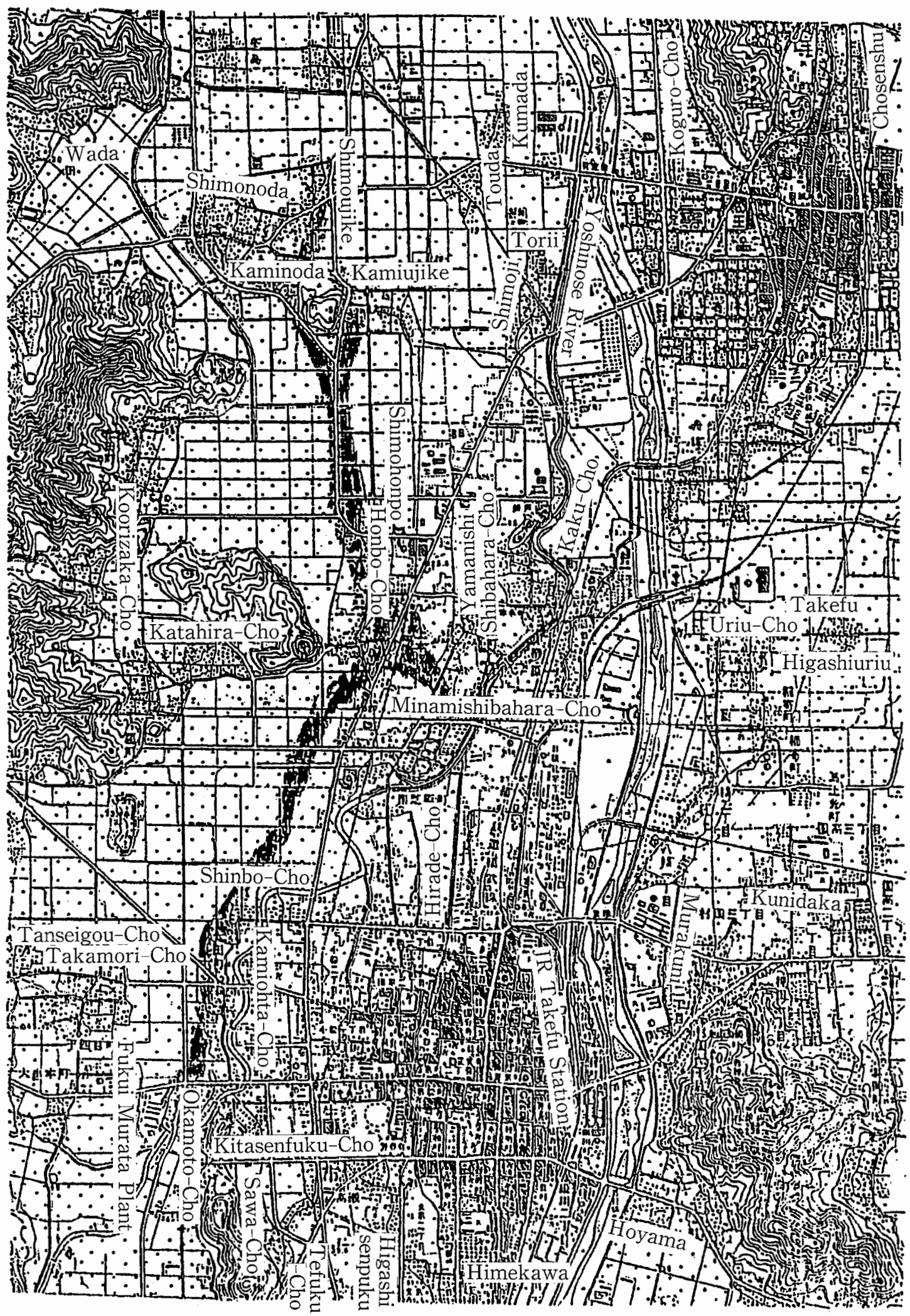

Map. 4. The Groundwater Pollution at Takefu City 


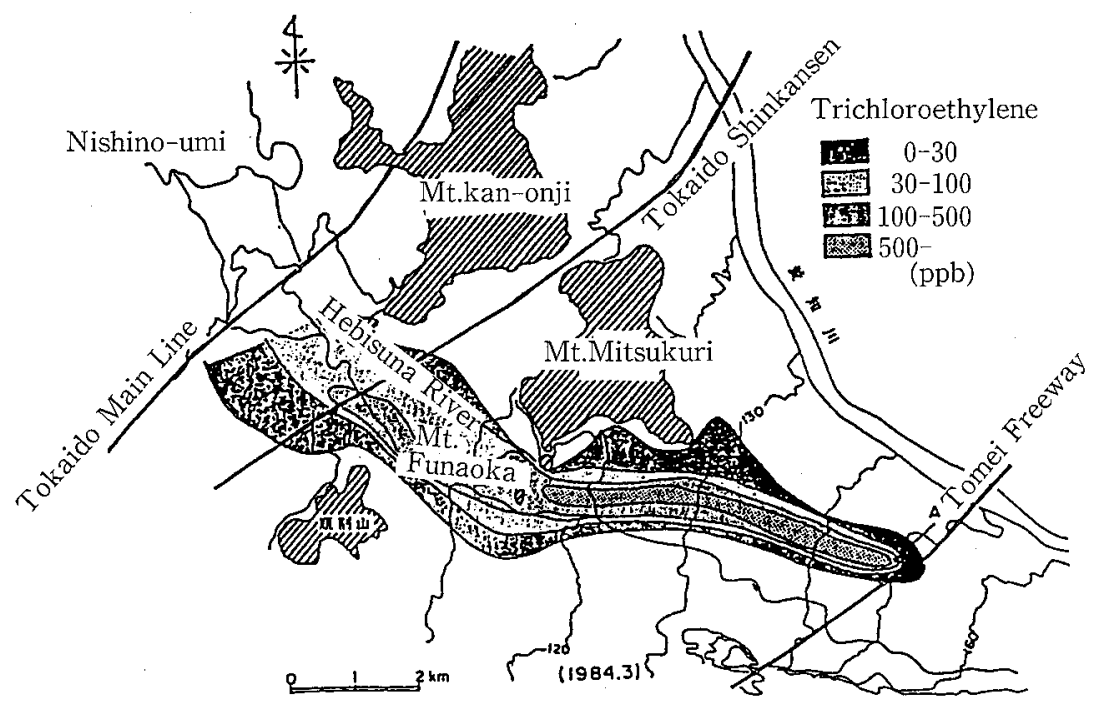

Map. 5. The Groundwater Pollution near Yohkaichi Trichloroethylene (ppb) 1984 (Japan Water Pollution Research Association, 1986) 